\title{
A rare case of thyroid storm following caesarean section
}

\author{
Sanjay Singh*, Manash Biswas, Tony Jose, Madhusudan Dey, Monica Saraswat
}

Department of Obstetrics \& Gynaecology, Armed Forces Medical College, Pune, Maharashtra, India

Received: 22 January 2016

Accepted: 15 February 2016

\author{
*Correspondence: \\ Dr. Sanjay Singh, \\ E-mail: drsanjaysingh@gmail.com
}

Copyright: (c) the author(s), publisher and licensee Medip Academy. This is an open-access article distributed under the terms of the Creative Commons Attribution Non-Commercial License, which permits unrestricted non-commercial use, distribution, and reproduction in any medium, provided the original work is properly cited.

\begin{abstract}
Thyroid storm in pregnancy is a rare life threatening emergency, with very high maternal and perinatal mortality and morbidity. Here we present an unusual case of a 30 year-old G2P1L1 woman, a known case of post caesarean pregnancy with hyperthyroidism who presented with severe preeclampsia and on second post op day developed thyroid storm. Early recognition and timely institution of appropriate management resulted in good outcome in this case.
\end{abstract}

Keywords: Thyroid storm, Thyrotoxic crisis, Pregnancy, Hyperthyroidism, Preeclampsia

\section{INTRODUCTION}

Generally seen in patients with Graves' disease, thyroid storm also referred to as thyrotoxic crisis is a life threatening exacerbation of the hyperthyroid state characterized by multisystem involvement.1 Only 1-2\% hyperthyroid cases during pregnancy manifest as thyroid storm and the mortality range between $20-30 \%$ despite treatment. 2 It is abrupt in onset and is usually triggered by non-concordance with prescribed antithyroid medication or certain precipitants or stressful situation. 3 In cases of thyroid storm the value of thyroid hormone remains similar to that of uncomplicated cases of thyrotoxicosis only and treatment is recommended to be started on strong clinical suspicion, without waiting for lab reports to come.4 Appropriate and timely intervention reduces mortality and morbidity.

\section{CASE REPORT}

28 years G2P1L1, a known case of Graves' disease on tab Propylthiouracil (PTU) was referred from a peripheral hospital at 35 weeks 05 days period of gestation (POG) with uncontrolled hypertension $(220 / 120 \mathrm{~mm}$ of $\mathrm{Hg}$ ) for further management. She was symptomatic with headache on the day of admission. Her last menstrual period was on 25 Mar 2015 making her expected date of delivery 01 Jan 2016. She underwent caesarean delivery in her first pregnancy 4 years ago for thyrotoxicosis with severe preeclampsia. Patient was registered at 17 weeks 02 days POG. Routine antenatal investigations done were normal. Her blood group was B positive. Midtrimester sonography confirmed the correctness of expected date of delivery and ruled out any obvious anomaly. On her first antenatal visit only, she was found to be hypertensive (BP-150/100mm of $\mathrm{Hg}$ ) with raised $\mathrm{T} 3$ and $\mathrm{T} 4$ level (T3>800 ng/dl, T4 > $30 \mu \mathrm{g} / \mathrm{dl}, \mathrm{TSH}-0.09 \mu \mathrm{IU} / \mathrm{ml}$ ). Diagnosed as a case of chronic hypertension and thyrotoxicosis, she was put on tab labetalol and alpha methyl dopa. She was started on tab PTU $50 \mathrm{mg} \mathrm{1-0-1/2}$ for treating thyrotoxicosis (that she had stopped taking one year ago) and tab propranolol $20 \mathrm{mg}$ twice a day, in consultation with physician. In spite of counselling she remained non-compliant with irregular follow up.

At our tertiary care centre on evaluation she was found to have superimposed preeclampsia with severe intrauterine growth restriction and severe oligohydramnios. Urine for protein was 3+ by dipstick test. Inj MgSO4 was started as per Zuspan regimen for seizure prophylaxis and IV labetalol was administered for control of blood pressure. She underwent an emergency LSCS and delivered a female new-born baby of $1.8 \mathrm{~kg}$. 
On the second post op day she developed sudden onset breathlessness with wheeze, vomiting, agitated and delirious behaviour, profuse sweating, tachycardia (140160 BPM), severe hypertension (BP-220/120 mm Hg), tachypnea (RR- 28/min) and hyperpyrexia $\left(104^{\circ} \mathrm{F}\right)$. Applying the Burch Wartofsky score she was diagnosed as a case of thyroid storm with a score of $100(>25$ is diagnostic). Patient was shifted to ICU where she was managed in consultation with endocrinologist and intensivist with moist $\mathrm{O} 2$ inhalation, cooling by tepid water sponging, IV fluid, Inj labetalol, Inj lasix, Inj hydrocortisone, tab propranolol, increased dosage of tab PTU (200 mg three times a day) and nebulization. Antibiotic was augmented. Patient responded to this management. The acute phase was controlled. Thyroid profile done on the same day was found to be normal (T3-1.34 $\mathrm{mg} / \mathrm{dl}, \quad \mathrm{T} 4-7.21 \mu \mathrm{g} / \mathrm{dl}, \quad \mathrm{TSH} \quad 0.01 \mu \mathrm{IU} / \mathrm{ml}$ ). Detailed history taken from the patient after recovery revealed that she had not been taking PTU since last seven days.

After the acute phase was over she was put on tab amlodipine $10 \mathrm{mg}$ twice a day and tab minipress XL (prazosin) $1 \mathrm{mg}$ once a day. She was continued with tab PTU $100 \mathrm{mg}$ three times a day and planned for review after 3 weeks with repeat thyroid profile by endocrinologist.

\section{DISCUSSION}

The prevalence of hyperthyroidism during pregnancy is ranges from $0.1 \%$ to $0.4 \%$. Graves' disease accounts for around $85 \%$ cases of hyperthyroidism during pregnancy. ${ }^{5}$ Maternal hyperthyroidism is associated with an increased risk of pre-eclampsia, maternal heart failure, maternal death, spontaneous abortion, preterm delivery, low birth weight, stillbirth and perinatal mortality $(6-12 \%){ }^{6}$ Our case was associated with preeclampsia, preterm delivery, and low birth weight. The risk of complications for both the mother and the fetus is related to the duration and control of maternal hyperthyroidism. Our non-compliant patient is a good example. Because normal pregnancy simulates some clinical findings similar to thyroxine (T4) excess, clinically mild thyrotoxicosis may be difficult to diagnose. Some important symptoms and signs include failure in non-obese woman to gain weight despite normal or increased food intake, heat intolerance, irritability, tachycardia, thyromegaly and exophthalmos. All these symptoms and signs except exophthalmos were present in our case. Overt thyrotoxicosis, is characterized by excess thyroid hormones in serum and suppressed TSH $(<0.01 \mathrm{mU} / \mathrm{L})^{7}$

Thyroid storm is an acute and life threatening endocrine emergency. Though the exact prevalence of thyroid storm is not known, because of variability in diagnostic criteria, it may account for <1-2\% hyperthyroid cases. The mortality of this condition is still high, ranging from 20 to $30 \%$, despite treatment. ${ }^{2}$
Table 1: Burch and Wartofsky's scoring system: A score of $\mathbf{4 5}$ or more is highly suggestive of thyroid storm, a score of 25 - 44 supports the diagnosis and a score below 25 makes thyroid storm unlikely.

\begin{tabular}{|c|c|}
\hline Parameters & Scoring \\
\hline \multicolumn{2}{|l|}{ Thermoregulatory dysfunction } \\
\hline \multicolumn{2}{|l|}{ Oral temperature $\left({ }^{\circ} \mathrm{F}\right)$} \\
\hline $99-99.9$ & 5 \\
\hline $100-100.9$ & 10 \\
\hline $101-101.9$ & 15 \\
\hline $102-102.9$ & 20 \\
\hline $103-103.9$ & 25 \\
\hline 104 & 30 \\
\hline \multicolumn{2}{|l|}{ Cardiovascular dysfunction } \\
\hline \multicolumn{2}{|l|}{ Tachycardia } \\
\hline $90-109$ & 5 \\
\hline $110-119$ & 10 \\
\hline $120-129$ & 15 \\
\hline $130-139$ & 20 \\
\hline$>140$ & 25 \\
\hline \multicolumn{2}{|l|}{ Congestive heart failure } \\
\hline Absent & 0 \\
\hline Mild (pedal oedema) & 5 \\
\hline Moderate (Bibasal rales) & 10 \\
\hline Severe (pulmonary oedema) & 15 \\
\hline \multicolumn{2}{|l|}{ Atrial fibrillation } \\
\hline Absent & 0 \\
\hline Present & 10 \\
\hline \multicolumn{2}{|l|}{ Central nervous system symptoms } \\
\hline Absent & 0 \\
\hline Mild agitation & 10 \\
\hline $\begin{array}{l}\text { Moderate (Delirium, psychosis, extreme } \\
\text { lethargy) }\end{array}$ & 20 \\
\hline Severe (Seizure, coma) & 30 \\
\hline \multicolumn{2}{|l|}{ Gastrointestinal /hepatic dysfunction } \\
\hline Absent & 0 \\
\hline $\begin{array}{l}\text { Moderate (Diarrhoea, nausea, vomiting, } \\
\text { abdominal pain) }\end{array}$ & 10 \\
\hline Severe (Unexplained jaundice) & 20 \\
\hline \multicolumn{2}{|l|}{ Precipitating event } \\
\hline Absent & 0 \\
\hline Present & 10 \\
\hline
\end{tabular}

Precipitants of thyroid storm in a previously compensated thyrotoxicosis case include abrupt cessation of antithyroid drugs, thyroid, or nonthyroidal surgery and a number of acute illnesses unrelated to thyroid disease such as severe infection, anaemia, severe pre-eclampsia, labour and several others. ${ }^{3,8}$ In our case the probable precipitants were abrupt cessation of PTU, severe preeclampsia and caesarean section. Thyroid storm also occurs rarely following radioactive iodine therapy.

Thyroid storm is not an entity distinct from thyrotoxicosis, but rather one end of a spectrum of severity of hyperthyroidism. Patients with thyroid storm 
have an exaggeration of the usual symptoms of hyperthyroidism. This may be easily confused with hypertensive encephalopathy, CNS infections, heart failure, sepsis, panic disorder and pheochromocytoma. Precise criteria for thyroid storm have been defined by Burch HB, Wartofsky (Table 1). ${ }^{9}$ This includes tachycardia, arrhythmias, congestive heart failure, hypotension, hyperpyrexia, agitation, delirium, psychosis, stupor and coma as well as nausea, vomiting, diarrhoea and hepatic failure. A score of 45 or more is highly suggestive of thyroid storm, a score of 25 - 44 supports the diagnosis and a score below 25 makes thyroid storm unlikely. Our patient achieved a score of 100 which was highly suggestive of a thyroid storm. Laboratory test are not helpful in making the diagnosis of a thyroid storm, because the serum thyroxin and thyroid stimulating hormone levels are the same as those of uncomplicated hyperthyroidism, as can be seen in our case.

A high index of suspicion for thyroid storm should be maintained in patients with thyrotoxicosis for its early diagnosis and aggressive management. The diagnosis is usually made on the basis of the clinical features alone. Treatment should be started immediately and should not be delayed for want of lab reports as we did. A multimodality treatment approach to patients with thyroid storm should be used, including beta-adrenergic blockade, antithyroid drug therapy, inorganic iodide, corticosteroid therapy, aggressive cooling with acetaminophen and cooling by tepid water sponging, volume resuscitation, correction of electrolyte imbalance if any, respiratory support, treatment of the underlying precipitating event and monitoring in an intensive care unit. ${ }^{7,10,11}$ We could not use inorganic iodide in our case because of its nonavailability.

The therapeutic options for thyroid storm are the same as those for uncomplicated hyperthyroidism, except that the drugs are given in higher doses and more frequently. Safety of the drugs during pregnancy is also given due consideration. The antithyroid drugs available are the thionamides that includes propylthiouracil (PTU), methimazole and carbimazole (which is metabolised to methimazole). All are effective and all have been used during pregnancy, whereas methimazole blocks new hormone synthesis, PTU also blocks T4 to T3 conversion. The recommended doses for PTU are $1000 \mathrm{mg}$ followed by $200 \mathrm{mg}$ every 6 hours (hr) and for methimazole 20-25 mg every 6 hours orally or via nasogastric tube. Transient leukopenia (10\%) and agranulocytosis (0.3-0.4\%) are known complications with thionamide treatment. It has been shown in recent studies that propylthiouracil and methimazole cross the placenta equally and result in an equal chance of inducing fetal or neonatal hypothyroidism. Hepatotoxicity is a potentially serious side effect of PTU that develops in 0.1 to $0.2 \%$. Methimazole has been associated with a rare methimazole embryopathy characterized by oesophageal and choanal atresia. American Association of Clinical Endocrinologists thus recommends PTU therapy during the first trimester followed by methimazole beginning in the second trimester.

An hour or two after initial thionamide administration, iodide is given to inhibit thyroidal release of T3andT4. It can be given intravenously as sodium iodide $(500-100 \mathrm{mg}$ IV every $8 \mathrm{hr}$ ) or orally as saturated solution of potassium iodide (5gtt PO every $8 \mathrm{hr}$ ) or lugol solution $10 \mathrm{gtt}$ PO every $8 \mathrm{hr}$ ).With a history of iodine induced anaphylaxis , lithium carbonate, $300 \mathrm{mg}$ every 6 hours may be given.

Beta blockers like propranolol, labetalol or more specific short acting beta blocker - esmolol are used to inhibit the adrenergic effects of excessive thyroid hormone on the cardiovascular system. 10-40mg of propranolol may be given PO every 4-6 hours. It is to be noted that b-blockers are contraindicated in presence of severe heart failure and shock. Supraventricular arrhythmias should be managed with current antiarrhythmic therapy (adenosine, overdrive pacing) if not responsive to b-adrenergic blockade. Treatment of congestive heart failure if present, also need attention.

Corticosteroid therapy for 24 hours (hydrocortisone $100 \mathrm{mg}$ IV every $8 \mathrm{hr}$ or dexamethasone $2 \mathrm{mg}$ every $8 \mathrm{hr}$ ) is recommended to further block peripheral conversion of T4 to T3.

Appropriate supportive management as mentioned above and treatment of precipitating factors e.g. infection, pre eclampsia, anaemia or any other factor present, is equally important. Close assessment and continuous maternal cardiac monitoring in an intensive care setting is required. $^{10}$

\section{CONCLUSIONS}

Thyroid storm is an acute, life-threatening, hyper metabolic state in individuals with thyrotoxicosis. Diagnosis is primarily clinical, and no specific laboratory tests are available. Several factors may precipitate the progression of thyrotoxicosis to thyroid storm. Because thyroid storm is almost invariably fatal if left untreated, rapid diagnosis and aggressive treatment is fundamental in limiting the maternal, fetal and neonatal morbidity and mortality associated with this condition.

\section{Funding: No funding sources \\ Conflict of interest: None declared \\ Ethical approval: Not required}

\section{REFERENCES}

1. Tietgens ST, Leinung MC. Thyroid storm. Med Clin North Am. 1995;79:169-84.

2. Davis LE, Lucas MJ, Hanklins GDV. Thyrotoxicosis complicating pregnancy. Am J Obstet Gynecol. 1989;160:63-70. 
3. Nayak B, Burman K. Thyrotoxicosis and thyroid storm. Endocrinol Metab Clin North Am. 2006;35:663-86.

4. Sarlis JN, Gourgiotis. Thyroid Emergencies. Rev End Metab Dis. 2003;4:129-36.

5. Marx H, Amin P, Lazarus JH. Hyperthyroidism and pregnancy. BMJ. 2008;336:663-7.

6. Kriplani JL, Buckshee K, Bhargava VL. Maternal and perinatal outcome in thyrotoxicosis complicating pregnancy.Eur J Obstet gynecol Reprod Biol. 1994;54:159.

7. Bahn RS, Burch HB, Cooper DS. Hyperthyroidism Management Guidelines, Endocr Pract. 2011;17(3).

8. Abalovich $\mathrm{M}$, Amino $\mathrm{N}$, Barbour L, et al. Management of thyroid dysfunction during and after pregnancy. An endocrine society clinical practice guideline. J Clin Endocrinol Metab. 2007;92(8):S147.

9. Burch HB, Wartofsky L. Life-threatening hyperthyroidism: Thyroid storm. Endocrinol Metab Clin North Am. 1993;22:263-77.

10. Fitzpatrick D, Russel M. Diagnosis and management of thyroid disesase in pregnancy. Obstete Gynecol Clin North Am. 2010;37:173.

11. Cunningham FG, Leveno KJ, Bloom SL. Endocrine disorders. In: Williams Obstetrics $24^{\text {th }}$ edition. Mc Graw Hill. 2014:1147-52.

Cite this article as: Singh S, Biswas M, Jose T, Dey $\mathrm{M}$, Saraswat M. A rare case of thyroid storm following caesarean section. Int J Reprod Contracept Obstet Gynecol 2016;5:933-6. 